\title{
Consultations with interest groups and the empowerment of executives: Evidence from the European Union
}

Adriana Bunea, University College London

Robert Thomson, University of Strathclyde

Accepted for publication in Governance: An International Journal of Policy, Administration and Institutions

We examine how an executive's consultations with interest groups during the formative stage of the policy process affect its bargaining success during the decision-making stage after it has proposed new policies to legislative actors. Our theory sets out how consultations with interest groups strengthen the executive by bolstering its formal and informal agenda-setting power. The empirical testing ground for our theory is the European Union (EU), and in particular the consultations held by the European Commission. The analysis assesses the effects of these consultations on the congruence between the Commission's legislative proposals on controversial issues and EU laws. Our analysis incorporates detailed information on the type and scope of each consultation. In line with our theory, we find that the Commission had more success during the decision-making stage after conducting open consultations with large numbers of interest groups during the policy formation stage. 


\section{Introduction}

This study examines the effect of executives' consultations with interest groups on the congruence between those executives' policy proposals and subsequent legislative outputs. The theoretical importance of this topic is that it refers to one of the sources of executives' influence in legislative policymaking. For over a century, political scientists have recognized that interest groups play a prominent role in policymaking (Bentley 1908 [2008]; Truman 1951; Mackenzie 1955; Richardson ed. 1982; 2012), Policymakers in national and international political systems regularly consult affected stakeholders before formulating policy proposals (Rokkan 1966; Knoke et al. 1996; Tallberg 2012; Coen and Richardson eds. 2009). Much existing research on interest groups provides valuable insights into the types of groups that exert influence, what their policy demands are, and the extent to which they influence policies. Our focus is distinct in that we examine how consultations with interest groups affect the bargaining success of the policymakers that engineer those consultations.

We argue that executives consult interest groups partly to improve their own bargaining success relative to legislative actors during subsequent policy negotiations with legislatures. Two mechanisms put executives in a strong position in relation to legislators when they consult before introducing proposals. The first refers to formal agenda-setting power (Romer and Rosenthal 1978; Tsebelis and Garrett 2000). To use their formal agenda-setting power effectively, executives must have accurate and comprehensive information on the preferences of legislators, and executives can gather such information during consultations with affected interests. The second mechanism refers to executives' informal bargaining power. This includes their ability to persuade legislators, to which Kingdon refers as their "claim to a hearing" (1984: 180-1). The argument here is that after consulting interest groups, executives can claim more legitimacy and 
technical expertise than they otherwise could (Mörth 2009). We develop and test these arguments in the context of policymaking in the European Union, specifically consultations held by the EU's main executive in legislative decision-making, the European Commission. Before doing so, the next section sets out our main theoretical argument.

\section{How consultations with interest groups empower executives}

Executives formulate legislative proposals that are then considered for adoption by legislative actors. Executives' policy preferences often differ from those of legislative actors. This is true in presidential systems where executives and legislators are elected separately (Linz 1990). It is also true in fused systems in which the executive is installed by the legislature after legislative elections (Laver and Shepsle 1996). Executives are at the apex of bureaucracies, which have their own goals, such as enhancing bureaucratic autonomy and preserving existing policy routines (Carpenter 2001), and this also characterizes the political system of the EU (Ellinas and Suleiman 2012). For the purposes of our inquiry, what matters is that the policy preferences of executives and legislators often differ (not necessarily that they are at odds), and that executives seek to ensure that legislative outputs reflect their policy preferences.

Theories of agenda setting distinguish between formal and informal agenda-setting power (Pollack 1997: 121; Moravcsik 1999). An agenda setter that consults can use both types of agenda power more effectively. The formal agenda-setting power of the executive consists of its right to initiate proposals. Formal models of legislative procedures focus specifically on the agenda setter's formal agenda-setting power and how this power is constrained by the procedural rules that apply during the decision-making stage (e.g. Romer and Rosenthal 1978; Tsebelis and Garrett 2000). A key assumption of such models is that the agenda setter uses its knowledge of 
legislators' policy preferences when crafting its policy proposals. The agenda setter chooses a policy alternative that is as close as possible to its own policy preference, while receiving enough support from the legislative actors to pass. To achieve this, the agenda setter needs detailed and accurate information on the policy preferences of those legislators. Holding consultations with relevant stakeholders is one way of gathering this information, certainly if legislators are influenced by the same groups that participate in consultations.

Informal agenda-setting power refers to an agenda setter's ability to act as a "policy entrepreneur" so as "to set the substantive agenda of an organization, not through its formal powers but through its ability to define issues and present proposals that can rally consensus among the final decision makers" (Pollack 1997: 121). The idea of policy entrepreneurship is linked to a broader range of sources of power that are relevant beyond formal settings. A successful policy entrepreneur is an actor with: (1) a "claim to a hearing" resulting from its expert knowledge and the ability to speak on behalf of powerful interest organizations; (2) an ability to negotiate skillfully; and (3) persistence in pursuing policy change and persuading other policy actors (Kingdon 1984: 180-1). With respect to the assembly of relevant expertise, consultations can be viewed as large-scale brainstorming exercises that increase policymakers' analytical capacity and ability to tackle policy problems, which represents a key aspect of administrative power (Heclo 1974: 305). In contrast to formal agenda-setting power, informal agenda-setting power relates to effectiveness in informal negotiation processes (Hunold 2001).

These arguments in relation to formal and informal agenda-setting power have distinct observable implications. The argument in relation to formal agenda-setting power was that consultations give the executive additional information on the preferences of the legislative actors, which allow it to more accurately take these into account when formulating its legislative 
proposals. If this were the case, we would expect to observe a difference between legislative proposals on which the executive consulted and those on which it did not consult in terms of the agreement between those proposals and legislative actors' policy preferences. Specifically, if consultations improve the executive's bargaining success by increasing its formal agenda-setting power, we would expect to find the following:

H1: The executive's policy proposals have more effective support from legislative actors when it previously consulted with relevant interest groups than when it did not.

The research design below gives more detail on our measure of effective support from legislative actors, which is based on the proportion of formal voting power held by legislative actors who support the executive's proposal and who attach a high level of salience to the issue in question.

The argument in relation to informal agenda-setting power refers to policy entrepreneurship, and a range of sources of power relevant to informal negotiations. The argument here is not about how the executive adjusts the contents of its policy proposals in response to the policy preferences of legislators, as is the case with formal agenda-setting power. Rather, it is that the executive has greater bargaining success despite a given level of resistance from other actors when it consulted than when it did not consult. Of course, bargaining success is not an indication of power if the "successful" executive has simply adapted its proposal to anticipate a compromise among legislators. Our analyses therefore control for the level of effective support for the executive's proposals when examining the effect of consultations. If consultations improve the executive's bargaining success by increasing its informal agendasetting power, we would expect to find evidence for the following hypothesis: 
H2: Even after controlling for the level of effective support from legislative actors, the executive has more bargaining success relative to legislative actors when it previously consulted with relevant interest groups than when it did not.

We now turn to how these expectations apply to consultations with interest groups in the European Union. In doing so, we also identify some additional variables for which we control in the analyses.

\section{Consultations in the European Union}

We examine whether the Commission has more bargaining success relative to the legislative actors during the decision-making stage when it consulted on its proposals during the prior policy formation stage. The Council of the EU, in which member states are represented, and the directly elected European Parliament (EP), are the EU's legislative actors. In most of the cases we examine, the Council and EP share co-decision power, as is now usually the case under the ordinary legislative procedure.

The EU is an appropriate testing ground for several reasons. First, there is considerable variation in whether or not and the ways in which the Commission consults with affected stakeholders when formulating legislative proposals. This variation provides an opportunity to compare cases with different levels and forms of consultation. Second, information on consultations has become increasingly available for research purposes. Third, we have a considerable amount of detailed information on the policy positions of the Commission and each of the main legislative actors, as well as decision outcomes, for a sample of legislative proposals in the form of the DEUII dataset (Thomson et al. 2012). Using this dataset we identify whether and the extent to which the Commission's legislative proposals were congruent with the contents 
of the laws that were subsequently adopted. We are also able to control for the degree of support the Commission received from each of the legislative actors. This allows us to draw inferences about whether the EU's executive was in a stronger position relative to legislative actors after it held consultations.

Consultations are a long-established practice in EU policymaking, but the relevant rules and principles were not formalized until 2001 (EC 2001). According to the Commission, consultations should be held on legislative proposals that require an extended impact assessment, which is required for proposals that "result in substantial economic, environmental and/or social impact on a specific sector" (EC 2002: 15). The Commission's consultations can take a variety of forms, including closed or "targeted" consultations with carefully chosen stakeholders that have particularly relevant interests or areas of expertise, and open consultations in which the Commission announces a general consultation call to which any stakeholder or individual can respond online. The two formats of consultation are not mutually exclusive and are often used together. We identified 1,177 open consultations across all policy areas between 2001 and $2013 .{ }^{1}$

The Commission has considerable discretion on whether to hold consultations and the form they take. These decisions are taken within each Directorate General (DG), the main organizational units within the Commission. The official guidelines only require the inclusion of "targeted groups" in the consultations, while ensuring "adequate awareness-raising publicity" (EC 2002: 20). A highly placed policy officer in the Commission confirmed this situation: "It is up to the Commission service that is responsible for the preparation of the proposal to decide what the best consultation strategy for that proposal is."

As an example, consider the consultation held by the Commission prior to the introduction of the legislative proposal for a regulation setting emission performance standards 
for new passenger cars as part of the EU's integrated approach to reducing $\mathrm{CO}_{2}$ emissions from light-duty vehicles (COD/2007/297). This is one of the 54 legislative proposals included in our analyses and it represented an important development in the EU environmental policy. The Commission organized an online consultation between February and July 2007. When issuing its call for responses, the Commission identified a set of specific issues on which it sought stakeholders' views. These consisted of detailed issues, such as measures to be taken to ensure that the proposed target of $120 \mathrm{~g} / \mathrm{km}$ for the reduction of $\mathrm{CO}_{2}$ emissions is reached, the time frame for reaching the targets, and whether to include commercial vans in the regulation. A total of 45 interest groups participated in this online consultation. Two broad advocacy coalitions emerged during this consultation: organizations representing the European car manufacturing industry and those representing environmental NGOs. This consultation, like others, provided the Commission with a wealth of information on the support for different policies, as well as stakeholders' views on the likely effects of different policy options.

Our focus on the effects of such consultations on the European executive's bargaining success during the subsequent decision-making stage is distinct from and complements existing research on consultations in the EU. Existing research focuses mainly on the inputs into these consultations, including the balance of interests that participate. These studies highlight the importance of consultations in the EU as part of the European-level system of interest intermediation and representation (e.g. Quittkat 2011; Rasmussen and Alexandrova 2012; Rasmussen and Caroll 2014). Despite the lack of systematic comparative research on the effects of consultations on policy outputs, existing research on EU lobbying suggests that consultations matter in this respect. Resource exchange theory posits that during interactions between interest groups and policymakers, groups are granted access, voice and policy influence, while the 
Commission receives expert knowledge and input legitimacy (Bouwen 2004; Kohler-Koch and Finke 2007: 206-211; Coen 2009: 152). The first part of the exchange, in which stakeholders receive access, voice and legitimacy, is relatively well documented by scholarship on EU interest groups (Bouwen 2002, Coen 2009, Dür and Mateo 2012, Coen and Katsaitis 2013). However, little is known about the second part, which refers to whether the Commission actually benefits from its extensive consultations with stakeholders.

The theoretical propositions formulated in the last section are readily applicable to the European Commission's consultations. To make effective use of its formal agenda-setting power, the Commission needs accurate information on the policy positions of the main legislative actors: the Council and the EP. Consultations with stakeholders including interest groups are a potential source of such information, since legislative actors formulate their policy positions at least partly in response to demands expressed by those stakeholders. Many interest groups that participate in EU-level consultations are powerful at the domestic level and shape the positions taken by their national governments. Liberal theory leads us to expect that the balance of domestic interests shape states' policy positions (Moravcsik 1997: 518). The EP is also an important venue for interest group lobbying. Therefore, when the Commission consults with stakeholders during the formulation of its legislative proposals, it can formulate these proposals using information on legislative actors' policy positions that is as accurate as possible. This would lead us to expect evidence for the first hypothesis, which implies that consultations lead to a closer alignment of the Commission's policy proposals on the one hand, and member states and the EP's policy preferences on the other. ${ }^{3}$

Informal agenda-setting power is particularly relevant to the EU given the importance of informal governance in legislative decision-making (Christiansen et al. 2003; Héritier 2012; Reh 
et al. 2013). There is broad agreement that the Commission frequently acts as a policy entrepreneur (Mazey and Richardson 2006; Majone 1996: 74; Pollack 1997; Radaelli 2000: 26). Consultations are relevant to all three characteristics of an agenda setter's entrepreneurship. Regarding the first characteristic, the Commission's "claim to a hearing", consultations enable the European executive to present itself as the voice of stakeholders affected by the legislative initiative. Following consultations, the Commission can claim more legitimacy for the policy positions it takes during the decision-making stage. Moreover, consultations provide expert knowledge and therefore enable the Commission to claim that its positions are likely to be effective in the sense that they will be complied with and bring about their intended results (Crombez 2002). Consultations also strengthen the Commission in terms of the second characteristic of policy entrepreneurship, the ability to negotiate skillfully. They give the Commission access to policy-relevant expertise on the effects of alternative policies, which provides it with an information advantage and technocratic legitimacy (Radaelli 2000: 27). Through consultations, the Commission may also accentuate the third characteristic of policy entrepreneurship identified by Kingdon: persistence. Commission officials view themselves as "custodians" of the collective European interest (Ellinas and Suleman 2012). Consultations are part of a self-legitimization process that is common to all bureaucratic organizations. Having consulted widely with expert groups and affected interests during the policy formation stage, Commission officials perceive themselves to be entitled to pursue their policy proposals vigorously. This would lead us to expect evidence for the second hypothesis, which implies a positive effect of consultations on the Commission's bargaining success, even after controlling for the level of support for the Commission's proposals from legislative actors. 
The following analyses also consider several additional characteristics of consultations and proposals that may be relevant, some of which are specific to the EU. First, we control for different types of consultations. Existing research on EU consultations notes the distinction between open, usually online consultations, and more restricted, closed consultations with selected groups, such as expert committees or high level groups (Mazey and Richardson 2006: 250). We also distinguish among open consultations in terms of their scale and diversity. As detailed below, larger consultations tend to be more diverse in terms of the types of stakeholders involved and the range of member states from which they originate. Larger consultations may be more effective in strengthening the Commission's claim that it consulted widely and obtained a breadth of relevant policy information. Second, we compare cases in terms of their information intensity, which refers to the level of specialist technical expertise required to participate in policymaking (Bendor et al. 2001: 242). Such expertise is often cited as a source of interest groups' influence and is therefore relevant to include. Finally, as part of the robustness tests the analyses also consider the type of EU legal instrument and legislative procedure used.

\section{Research design}

The following analyses focus on 151 controversial issues raised by 54 legislative proposals that were first discussed in the Council after the 2004 enlargement. These proposals were initially selected as part of the DEUII dataset (Thomson et al. 2006; 2012). From the 125 proposals included in the DEUII dataset, we study the 54 that were first discussed after the 2004 enlargement, which means that we include only proposals that were introduced after the Commission's new approach to consultations started in 2001. 
In a series of semi-structured interviews with key informants, each controversial issue that featured in the discussions at the decision-making stage was reconstructed spatially. A total of 232 semi-structured interviews were held on the post-2004 part of the DEU project on which the present analysis is based. The interviewees were mainly officials from the permanent representations of the member states and from the Commission, who were involved in the decision-making on the cases selected. These interviews lasted an average of 65 minutes. During these interviews, key informants provided information on the issues that were controversial, the policy positions most favored by each of the relevant decision makers, and the levels of importance each actor attached to each issue. Each controversial issue was represented as a policy scale, with the numbers 0 and 100 at the endpoints of each scale representing the most extreme positions considered in relation to each issue. Key informants identified the policy positions most favored by each of the legislative actors and the Commission at the time of the introduction of the legislative proposal. Informants also estimated the level of salience each actor attached to each issue, again on a scale from 0 to 100 . Detailed discussions of this approach appear in several existing publications (Thomson et al. 2006; 2012). Two previous publications tested the reliability and validity of the key informants' judgments used in the present study with satisfactory results (Thomson et al. 2006: 329-47; König et al. 2007). These tests consisted of comparing key informants' judgments with information from documentation and comparing key informants' judgments with each other. For instance, König et al. (2007: 294) examined the point location of thirty-nine policy positions from seven of the issues included in the present study that were the subject of negotiation between the Council and the EP in conciliation committees. They compared the estimates of the key informants used for the present study with estimates from 
informants in the EP: either rapporteurs or their legislative assistants. They found that thirty-five of the thirty-nine estimates matched perfectly or almost perfectly.

Table 1 illustrates the data we use with two issues raised by the proposed regulation on the reduction of $\mathrm{CO}_{2}$ emissions of passenger cars (COD/2007/297). This proposal followed the consultations mentioned above, and these particular issues also featured in the prior consultation stage. The first issue concerns the parameter that should be used to decide which cars would be covered by the regulation. Two main policy positions were expressed on this issue: position 0 indicates that vehicle mass (weight) should be used as a parameter, while position 100 indicates that the vehicle footprint should be used instead. While the vehicle mass was generally considered to have benefited the industries producing heavier cars that pollute more, vehicle footprint was considered to benefit producers of lighter vehicles that pollute less. Countries producing heavier automobiles such as Austria, the Czech Republic, Germany, Poland and Romania have adopted the vehicle mass position, which was also expressed by the European Commission. This was also the policy option having the broadest support among interest groups participating in the open consultation. Countries opting for the vehicle footprint as a utility parameter were those countries that either had a well-developed light-weight vehicle industry or were supporters of the more environmental friendly option. The EP also supported this more environmentally friendly option. The outcome of the Council decision-making process favored the option supported by the Commission and the supporters of mass as a utility parameter. While this case is consistent with our expectation that the Commission has more bargaining success when it consulted, the following analyses examine whether this holds across a broad range of issues.

\section{[Table 1]}




\section{Analysis}

Before testing our hypotheses, we examine the type, occurrence and scope of the consultations that were held on our selected cases. In line with previous research we distinguish between closed and open consultations (Quittkat 2011: 658; Greenwood 2007); we identified this information in the explanatory memorandum in each legislative proposal (which was released after the consultations). The Commission held some form of consultation, either closed, open or both in the majority of cases: in 38 of the 54 legislative proposals selected for study, which included 113 of the 151 controversial issues raised. Closed consultations were somewhat more frequent than open consultations, although the Commission often held both closed and open consultations. The Commission held closed consultations without holding open consultations on 13 proposals (with 39 issues), open consultations without closed consultations on 8 proposals (with 23 issues) and both types on 17 proposals (with 51 issues). This gives us a reasonable number of observations with which to distinguish the effects of different types of consultations on the Commission's bargaining success.

The legislative proposals on which the Commission held consultations have a higher level of information intensity or complexity than proposals on which it did not consult. We measured information intensity by the number of recitals in the legislative proposal. Recitals precede the main body of the proposal and state the principles and assumptions on which the legislation is based, and often refer to other laws to which the present one relates. Similarly, Kaeding (2006: 236) used the number of recitals to measure the amount of detail in laws. The proposals on which the Commission consulted had an average of 29.88 recitals (s.d. 18.38; $\mathrm{n}=38$ ), while the proposals on which the Commission did not consult had an average of 19.19 
recitals (s.d. $18.31 ; n=16 ; p=.01$ from the rank test). There is also a significant difference in the same direction between the proposals on which the Commission held open consultations and those on which it did not. There is also a difference in the same direction, although not a significant one, between proposals on which the Commission held closed consultations and those on which it did not. The theoretical relevance of this finding is that it suggests the Commission consults with interest groups to take advantage of their specialist technical expertise, which is particularly valuable in relation to proposals with a high level of information intensity. This finding also means that information intensity should be included as a control variable in analyses of the effects of consultations on the Commission's bargaining success.

Open consultations vary considerably in terms of the numbers of stakeholders that participated. The numbers of stakeholders are highly correlated with the diversity of stakeholders in terms of stakeholder type and country of origin. From the Commission's website and through written requests to Commission services, we gathered information on participating stakeholders' characteristics, specifically: (1) the total number of groups that participated; (2) the number of public and private interest groups consulted; ${ }^{4}$ and (3) each group's country of origin, if any. While we were able to obtain information on the numbers of interest groups that participated in 24 of the 25 open consultations selected for study, we could obtain detailed information on the type of groups consulted on 20 of the consultations and on the origin of the groups in 16 of the consultations. The total number of groups is highly correlated with both the number of public interest groups and private interest groups; the Spearman rho correlations are $.58(\mathrm{p}<.01 ; \mathrm{n}=20)$ and $.72(\mathrm{p}<.01 ; \mathrm{n}=20)$ respectively. Similarly, the total number of groups consulted is highly correlated with the diversity of groups in terms of their country of origin. We constructed a measure of the number of member states included in the countries of origin of the participating 
groups. The total number of groups is highly correlated with this measure of groups' breadth of origin (Spearman rho correlation .86; $\mathrm{n}=16 ; \mathrm{p}<.01$ ). Given these very high correlations and our desire to include as many observations as possible, we focus on the number of groups that participated as a proxy for both the scale and diversity of open consultations.

The number of stakeholders that participated in the consultations is highly skewed. Across the 24 proposals on which we have information on the numbers of groups that participated, the smallest number is 4 and the largest number is 1,246 (average 174.42; s.d. 254.47). We transformed this variable into a categorical indicator and use that as an independent variable in the analysis of the Commission's bargaining success in the following section. This variable distinguishes among small open consultations involving between 1 and 50 groups (7 proposals with 25 issues), medium sized consultations involving 51 to 150 groups ( 9 proposals with 22 issues) and large consultations with over 150 groups (8 proposals with 23 issues). To ensure that the results are not driven by such coding decisions, we also applied a log transformation of the number of groups as one of several robustness tests and obtained substantively the same results.

Turning now to the first of our two hypotheses, we examine whether the Commission's consultations were followed by proposals that had more support from legislative actors. We constructed a measure of effective support for the Commission's policy proposal as follows. ${ }^{5}$

\footnotetext{
$\square$ voting power salience $_{a}$ $\frac{\{\text { position a }}{n}$

$\square^{n}$ voting power $_{a}$ salience $e_{a}$ 
where the actors from the decision stage are denoted $a, b, c, \ldots$ from the set $n$, and consist of the Commission, each of the member states in the Council, and the European Parliament. position $_{a}$ is the policy position of actor $a$ on the issue.

voting power $_{a}$ is the voting power of actor $i$ on the issue. In this application we use actors' Shapley-Shubik Power Index scores, which assigns a weight to each actor based on the legislative procedures. ${ }^{6}$

salience $_{a}$ is the level of salience that actor $a$ attaches to the issue.

This measure of effective support is the effective voting power (voting power times salience) that supports the Commission's position as a percentage of all effective voting power on the issue in question. It incorporates information on the positioning of the Commission relative to other actors, its relative salience for the issue, and the legislative procedure.

Contrary to Hypothesis 1, the cases on which the Commission consulted stakeholders do not differ significantly from those on which it did not consult in terms of effective support. Effective support was on average of 38.39 percent for issues from proposals on which the Commission consulted (s.d. $24.68 ; n=38$ issues), compared to 37.19 percent (s.d. $23.93 ; n=113$ ) for issues from proposals on which it did consult ( $\mathrm{p}=.94$ from the rank test). Similarly, there are no significant differences in the level of effective support for the Commission's proposals by the type of consultation it held. The theoretical significance of this non-finding is that there is no evidence that consultations empower the Commission by bolstering its formal agenda-setting power. Nonetheless, we expect effective support for the Commission's proposals to affect whether its positions are adopted as laws, and therefore control for effective support in the following analysis in which we examine the Commission's bargaining success. 
The Commission's bargaining success is defined as the level of congruence between the Commission's policy position on each issue and the decision outcome adopted in the final legislative act. We focus first on a dichotomous measure of the Commission's success, which identifies whether or not the Commission's policy position corresponded to the decision outcome. The advantage of this dichotomous measure is that it does not involve the comparison of the distances across the policy scales, which refer to substantively different issues. Table 2 shows that the Commission's success rate was significantly higher when it consulted openly than when it did not: 27 percent compared to 14 percent $(\mathrm{p}=.05)$. The difference in the Commission's success rate is only significant for cases in which open consultations were held compared to other cases. The difference is not significant for closed consultations, or for open and closed consultations combined.

The finding from Table 2 also holds for a continuous measure of the Commission's bargaining success: the absolute distance between the Commission's proposal and the decision outcome on each policy scale. This continuous measure of Commission success was on average 34.99 (s.d. 32.61 ) on the 74 issues on which it consulted openly, compared to 45.70 (s.d. 33.86) on the 77 issues on which it did not consult openly ( $p=.05$ from the rank test). The following analyses confirm the importance of open consultations with multivariate models that also control for effective support for the Commission's proposals from other legislative actors as well as the information intensity of each dossier.

\section{[Table 2]}

Model 1 in Table 3 is a logit model that uses the dichotomous measure of the Commission's bargaining success. Again, the main finding is that open consultations increase the Commission's bargaining success. Large consultations in particular have a marked positive 
effect. The exponentiated coefficient associated with large consultations (involving more than 151 groups) is 6.45 , indicating that the odds of Commission success are more than six times greater if the Commission held such large open consultations than if it did not consult openly. The effect of large consultations can also be expressed as a predicted probability, holding the other variables constant. ${ }^{7}$ When open consultations are not held, the predicted probability of Commission success is .11 (95 percent confidence interval (95\% CI): .02; .19). When open consultations involving more than 150 groups are held, the predicted probability of Commission success increases to .44 (95\% CI: .27; .61). Small open consultations involving up to 50 groups are also associated with significantly more success for the Commission, but the effect is weaker. Overall, the effect of holding open consultations has a positive and significant effect on the Commission's bargaining success.

\section{[Table 3]}

Model 1 also contains several other variables. Closed consultations do not have a significant effect on the Commission's bargaining success. As expected, "effective support for the Commission's policy positions" has a large positive effect. Every one-point increase in effective support raises the odds of Commission success by four percent. Effective support has an average of 37.95 percent (s.d. 24.01). Moving from one standard deviation below to one standard deviation above the average effective support increases the predicted probability of Commission success from .05 (95\% CI: .00; .10) to .23 (95\% CI: .08; .37). Viewed in terms of predicted probabilities, the size of this effect is smaller than that of holding large open consultations. Recall that effective support includes a large amount of information: the location of the Commission's policy positions relative to those of other actors, the salience of each issue to each of the actors, and the relative voting power of each of the actors. The fact that holding 
large consultations has a greater impact than this control variable implies that it is substantively very important. The information intensity of the legislative proposal, measured by the numbers of recitals, is also included as a control variable, and is insignificant.

We conducted a range of tests to check the robustness of our main finding regarding the positive effect of large open consultations on the Commission's bargaining success. First, we ran the same model with the continuous measure of the Commission's bargaining success. We analyzed this dependent variable with a Tobit model and the results are reported in Model 2 of Table 3. The Tobit model takes into account the bounded nature of this variable; by definition, it cannot be lower than zero or greater than 100 . The findings mirror almost exactly those of the logit model. The coefficient of -38.49 associated with the large open consultations variable indicates that when these take place, decision outcomes are on average 38.49 adjusted policy scale points closer to the Commission's policy proposals. In a second robustness test we reran Model 1 of Table 3 using King and Zeng's (2001) logistic regression estimator, which adjusts the standard errors for the biases that can result from rare events and small sample sizes, the latter of which applies to our study. The results were the same. In a third set of robustness tests, we ran the models in Table 3 with a log transformation of the number of groups involved in open consultations as an alternative to the three-group categorization. This log-transformed variable also had a significant and positive effect on the Commission's bargaining success, which indicates that our results are not driven by our particular coding decisions. ${ }^{8}$ In a fourth set of robustness tests, we ran the models in Table 3 with additional controls, consisting of the legislative procedure used and the type of legal instrument. Neither of these additional control variables was significant, and they did not alter the findings. Recall that our effective support 
variable already includes information on the legislative procedure. We present the models that include only those variables that are in our view theoretically compelling.

\section{Conclusions}

We argued and found that the executive's consultations with affected interests, particularly open consultations that are large and diverse, strengthen its bargaining success relative to legislative actors. We developed the argument by discussing executives' formal and informal agenda-setting power. Formal agenda-setting power consists of the executive using the legislative procedure and its knowledge of legislators' policy preferences to bring about decision outcomes that are as close as possible to its own policy preferences. According to this mechanism, the executive uses its right of initiative, in combination with information on amendment rules, the policy preferences of legislators, and the reversion point, to pitch its policy proposals optimally, so that decision outcomes are as close as possible to its preference. Models of formal agenda-setting power assume that executive agenda setters have full information on the policy preferences of legislative actors, with which agenda setters locate pivotal legislators (Romer and Rosenthal 1978; Tsebelis and Garrett 2000). We argued that information on legislators' policy preferences is not always readily available to the executive, and that consultations are a means of obtaining such information. An implication of this argument is that the location of the executive's legislative proposal relative to the policy preferences of legislative actors differs between proposals on which the executive consulted interest groups and proposals on which it did not. However, the evidence did not reveal any difference in the levels of effective support for the Commission's proposals on cases on which it consulted and cases on which it did not consult. 
This suggests that formal agenda-setting power is not the main mechanism through which consultations empower the European executive.

Informal agenda-setting power is equally important in our argument (Pollack 1997: 121; Moravcsik 1999). Informal agenda-setting power refers to the impact of consultations on the executive's ability to influence legislators (Kingdon 1984: 180-1). This ability is strengthened by the legitimacy the executive receives from consulting with affected interests and incorporating policy-relevant expertise (Mörth 2009). In line with this argument, the evidence shows that even after controlling for the level of effective support by legislators for the Commission's proposals, the Commission has more bargaining success when it consulted widely. This implies that consultations are not only associated with more bargaining success, but more bargaining success in the face of resistance from legislative actors. In other words, large consultations bolster the bargaining power of the Commission. Future research should attempt to disentangle the detailed mechanisms through which open consultations increase the Commission's bargaining power in the decision stage. Our findings suggest that these mechanisms lie mainly in the realm of informal bargaining.

\section{References}

Bendor, Jon, Amihai Glazer and Thomas Hammond. 2001. 'Theories of Delegation.' Annual Review of Political Science 4: 235-69.

Bentley, Arthur. 1908[2008]. The process of Government: A Study of Social Pressures. Originally published: Chicago: University of Chicago. 
Bouwen, Pieter. 2004. 'Exchanging Access Goods for Access: A Comparative Study of Business Lobbying in the EU Institutions.' European Journal of Political Research 43(3): 337369.

Bouwen, Pieter. 2002. 'Corporate lobbying in the European Union: the logic of access.' Journal of European Public Policy 9(3): 365-390.

Bueno de Mesquita, Bruce. 1997. 'A decision making model: Its structure and form.' International Interactions 23(3-4): 235-66.

Carpenter, Daniel P. 2001. The Forging of Bureaucratic Autonomy: Reputations, Networks, and Policy Innovation in Executive Agencies 1862-1928. Princeton: Princeton University Press.

Christiansen, Thomas. Andreas Fellesdal and Simona Piattoni. (2003) 'Informal Governance in the European Union: An Introduction'. ed. Thomas Christiansen and Simona Piattoni. Informal Governance in the European Union. Northhampton, MA: Edward Elgar, 1-21.

Coen, David and Alexander Katsaitis. 2013. 'Chameleon pluralism in the EU: an empirical study of the European Commission interest group density and diversity across policy domains.' Journal of European Public Policy 20(8): 1104-1119.

Coen, David and Jeremy Richardson (eds.). 2009. Lobbying the European Union. Oxford: Oxford University Press.

Coen, David. 2009. 'Business Lobbying in the European Union'. ed. David Coen and Jeremy Richardson. Lobbying the European Union. Oxford: Oxford University Press, 145- 168.

Crombez, Christophe. 2002. 'Information, Lobbying and the Legislative Process in the European Union.' European Union Politics 3(1): 7-32. 
Dür, Andreas and Gemma Mateo. 2012. 'Who lobbies the European Union? National interest groups in a multilevel polity.' Journal of European Public Policy 19(7): 969-987.

Ellinas, Antonis A. and Ezra Suleiman. 2012. The European Commission and Bureaucratic Autonomy: Europe's Custodians. Cambridge: Cambridge University Press.

European Commission. 2001. COM(2001) 428 'European Governance. A White Paper’.

European Commission. 2002. Communication from the Commission COM(2002) 704 'Towards a reinforced culture of Consultation and dialogue - General principles and minimum standards for consultation of interested parties by the Commission'.

European Commission. 2010. Communication from the Commission to the European Parliament, the Council, the European Economic and Social Committee and the Committee of Regions COM(2010) 543 'Smart Regulation in the European Union'.

European Commission. 2012. Commission Staff Working Document SWD(2012) 422 Review of the European Commission Consultation Policy, Accompanying the document Communication from the Commission to the European Parliament, the Council, the European Economic and Social Committee and the Committee of Regions 'EU Regulatory Fitness' COM(2012) 746.

Greenwood, Justin. 2007. Interest Representation in the European Union. Houndmills, Basingstoke, Hampshire: Palgrave Macmillan.

Heclo, Hugh. 1974. Modern Social Politics in Britain and Sweden. New Haven: Yale University Press.

Héritier, Adrienne. 2012. 'Formal and informal institutions in the EU's legislative process'. ed. Thomas Christiansen and Christine Neuhold. International Handbook of Informal Governance. Cheltenham: Edward Elgar, 335-411. 
Hunold, Christian. 2001. 'Corporatism, Pluralism and Democracy: Toward a Deliberative Theory of Bureaucratic Accountability' Governance: An International Journal of Policy, Administration, and Institutions 14(2): 151-167.

Kaeding, Michael. 2006. 'Determinants of Transposition Delay in the European Union.' Journal of European Public Policy 26: 229-53.

King, Gary and Langche Zeng. 2001. 'Logistic Regression in Rare Events Data.' Political Analysis 9(2): 137-163.

Kingdon, John W. 2003. Agendas, Alternatives and public policies. Second edition. New York: Longman.

Knoke, David, Franz Pappi, Jeffrey Broadbent and Yutaka Tsujinaka. 2006. Comparing Policy Networks: Labor Politics in the US, Germany and Japan. Cambridge: Cambridge University Press.

König, Thomas, Bjorn Lindburg, Sandra Lechner and Winfried Pohlmeier. 2007. 'Bicameral Conflict Resolution in the European Union: An Empirical Analysis of Conciliation Committee Bargains.' British Journal of Political Science 37(2): 281-312.

Linz, Stepan. 1990. 'The Perils of Presidentialism.' Journal of Democracy 1(1): 51-69.

Laver, Michael, Kenneth A. Shepsle. 1996. Making and Breaking Governments: Cabinets and Legislatures in Parliamentary Democracies. New York: Cambridge University Press.

MacKenzie, WJM. 1955. 'Pressure Groups in British Government.' The British Journal of Sociology 6(2): 133-48.

Majone, Giandomenico. 1999. 'The European Commission as regulator.' ed. Giandomenico Majone. Regulating Europe. London and New York: Routledge, 61-82. 
Mazey, Sonia. and Jeremy Richardson. 2006. 'Interest groups and EU policy-making: organizational logic and venue shopping'. ed. Jeremy Richardson. European Union: Power and Policy-making. Second edition. London: Routledge, 247-268.

Moravcsik, Andrew. 1997. 'Taking Preferences Seriously: A Liberal Theory of International Politics.' International Organization 51(4): 513-53.

Moravcsik, Andrew. 1999. 'A New Statecraft? Supranational Entrepreneurs and International Cooperation.' International Organization 53(2): 267-306.

Mörth, Ulrika. 2009. 'The Market Turn in EU Governance - The Emergence of Public-Private Collaboration' Governance: An International Journal of Policy, Administration, and Institutions 22(1): 99-120.

Pollack, Mark A. 1997. 'Delegation, agency and agenda-setting in the European Community.', International Organization 51(1): 99-134.

Rasmussen, Anne and Brendan J. Caroll. 2014. 'Determinants of upper-class dominance in the heavenly chorus: Lessons from Online Consultations.' British Journal of Political Science 44(2): 445-59.

Rasmussen, Anne and Dimiter Toshkov. 2013. 'The effect of stakeholder involvement on legislative duration: Consultation of external actors and legislative duration in the European Union.' European Union Politics 14(3): 366-87.

Rasmussen, Anne and Petya Alexandrova. 2012. 'Foreign Interests Lobbying Brussels: Participation of Non-EU Members in Commission Consultations.' Journal of Common Market Studies 50(4): 614-631. 
Radaelli, Claudio M. 2000. 'Policy Transfer in the European Union: Institutional Isomorphism as a Source of Legitimacy.' Governance: An International Journal of Policy and Administration 13(1): 25-43.

Reh, Christine. Adrienne Héritier, Edoardo Bressanelli and Christel Koop. 2013. 'The Informal Political of Legislation: Explaining Secluded Decision Making in the European Union.' Comparative Political Studies 46(9): 1112-1142.

Richardson, Jeremy (ed.) 1982. Policy Styles in Western Europe. Winchester, Mass.: George Allen and Unwin.

Richardson, Jeremy. 2012. 'New Governance or Old Governance? A Policy Style Perspective.' ed. David Levi-Faur. The Oxford Handbook of Governance. Oxford University Press, $311-24$

Romer, Thomas, and Howard Rosenthal. 1978. 'Political Resource Allocation, Controlled Agendas, and the Status Quo.' Public Choice 33(4): 27-43.

Quittkat Christine. 2011. 'The European Commission's Online Consultations: a Success Story?' Journal of Common Market Studies 49(3): 653-674.

Rokkan, Stein. 1966. 'Norway: Numerical democracy and corporate pluralism.' ed. Robert Dahl. Political Opposition in Western Democracies. New Haven: Yale University Press, 70115.

Tallberg, Jonas. 2012. 'Civil society and global democracy: an assessment.' ed. Caniele Archibugi, Mathias Koenig-Archibugi and Raffaele Marchetti. Global Democracy: Normative and Empirical Perspectives. Cambridge: Cambridge University Press, 210-32.

Thomson, Robert, Frans N. Stokman, Christopher H. Achen and Thomas König. 2006. The European Union decides. Cambridge: Cambridge University Press. 
Thomson, Robert., Javier Arregui, Dirk Leuffen, Rory Costello, James Cross, Robin Hertz, and Thomas Jensen. 2012. 'A new dataset on decision-making in the European Union before and after the 2004 and 2007 enlargements (DEUII).' Journal of European Public Policy 19(4): 604-22.

Truman, David. 1951. The Governmental Process: Political Interests and Public Opinion. New York: Knopf.

Tsebelis, George and Geoffrey Garrett. 2000. 'Legislative Politics in the EU.' European Union Politics 1(1): 9-36. 


\section{Tables}

Table 1: Controversial issues raised by the regulation of $\mathrm{CO}_{2}$ emissions of passenger cars (Decisionmaking stage).

Issue 1: What should define whether a car is covered in the regulation? (car parameters)

Position 0: Vehicle mass (outcome) COM AT CZ DE PL RO SK ES

Position 100: Vehicle footprint $\quad$ EP BE DK FI FR EL IE IT LU NL SI

Issue 2: What level of penalties should be imposed for excess emissions?

Position 0: Low

COM AT BE BU CY DK EE FI EL HU IE LV IT LU MT NL

PT RO SI SE UK

Position 60: Graduated (Outcome)

Position 100: High

EP CZ FR DE IT PL SK ES

Note: AT: Austria; BE: Belgium; CY: Cyprus; CZ: Czech Republic; DK: Denmark; EE: Estonia; FI: Finland; FR: France; DE: Germany; EL: Greece; HU: Hungary; IE: Ireland; IT: Italy; LV: Latvia; LT: Lithuania; LU: Luxembourg; MT: Malta; NL: The Netherlands; PL: Poland; PT: Portugal; SI: Slovenia; SK: Slovakia; ES: Spain; SE: Sweden; UK: United Kingdom; COM: Commission; EP: European Parliament. Not all MSs took a policy position on these issues.

Table 2. The Commission has greater bargaining success when it consults openly

\begin{tabular}{|c|c|c|c|}
\hline \multirow[b]{2}{*}{$\begin{array}{l}\text { Decision outcomes in line with the } \\
\text { Commission's policy positions? }\end{array}$} & \multicolumn{2}{|c|}{ Type of consultation } & \multirow[b]{2}{*}{ Total } \\
\hline & $\begin{array}{l}\text { None or } \\
\text { closed only }\end{array}$ & Open & \\
\hline No & $86 \%(66)$ & $73 \%(54)$ & $79 \%(120)$ \\
\hline Yes & $14 \%(11)$ & $27 \%(20)$ & $21 \%(31)$ \\
\hline Total & $100 \%(77)$ & $100 \%(74)$ & $100 \%(151)$ \\
\hline
\end{tabular}

NB: Frequencies in parentheses. Chi2 3.75; $\mathrm{p}=.05$. 
Table 3. The effects of prior consultations on the Commission's bargaining success

\begin{tabular}{lcccc}
\hline & $\begin{array}{c}\text { Model 1 } \\
\text { Logit }\end{array}$ & \multicolumn{2}{c}{$\begin{array}{c}\text { Model 2 } \\
\text { Tobit } \\
\text { b (s.e.) }\end{array}$} & $\mathrm{p}$ \\
\hline Closed consultations & $1.24(.49)$ & .59 & $2.57(8.29)$ & .76 \\
Number of groups consulted in open consultations & & & & \\
(reference group: no open consultation) & & & & \\
$1-50$ & $5.31(3.26)$ & .01 & $-24.71(11.56)$ & .03 \\
$51-150$ & $.73(.59)$ & .78 & $-2.71(11.07)$ & .81 \\
$>150$ & $6.45(3.38)$ & .00 & $-38.49(8.68)$ & .00 \\
Effective support for Commission's position & $1.04(.01)$ & .00 & $-.43(.13)$ & .00 \\
Information intensity & $.99(.02)$ & .51 & $.22(.21)$ & .29 \\
Constant & $.03(.03)$ & .00 & $55.89(8.92)$ & .00 \\
Log pseudolikelihood & -62.31 & & -558.28 & \\
Model 1 Wald chi2 (p) / Model 2 F (p) & $22.34(.00)$ & & $5.35(.00)$ & \\
n issues (proposals) & $147(53)$ & & $147(53)$ & \\
\hline
\end{tabular}

Note: The dependent variable in Model 1 is a dichotomous measure of whether the decision outcome is the same as (1) or different from (0) the Commission's policy position. The dependent variable in Model 2 is the absolute distance between the decision outcome and the Commission's position. Standard errors clustered by legislative proposals. 


\section{Notes}

${ }^{1}$ Sources: http://ec.europa.eu/yourvoice/consultations/index_en.htm and websites of EC DirectoratesGeneral.

${ }^{2}$ Correspondence with the European Commission, General Secretariat, July 15th, 2013.

${ }^{3}$ A recent study of the duration of legislative decision-making in the EU by Rasmussen and Toshkov (2013) may suggest a different relationship between consultations and support for legislative proposals. They found that legislative proposals preceded by consultations took longer to adopt, indicating that the legislative decision-making stage was more controversial, than proposals that were not preceded by consultations.

${ }^{4}$ We coded national agencies/ministries, local authorities, environmental and consumer NGOs as public interest groups, and business and professional (trade unions) organisations as private interest groups.

${ }^{5}$ This measure resembles a component of Bueno de Mesquita's (1997) expected utility model.

${ }^{6}$ We follow Thomson et al. (2006: 49) by defining the winning coalitions for the Shapley Shubik Index as follows. For legislative proposals subject to the codecision procedure with qualified majority voting in the Council, winning coalitions consist of a qualified majority of member states and the EP. For those subject to consultation and qualified majority voting, there are two types of winning coalitions: the first consists of a qualified majority of member states and the Commission, while the second consists of all member states. For proposals subject to consultation and unanimity, the winning coalition includes all member states. In this latter case, the Commission is never pivotal and has a formal voting power of zero.

${ }^{7}$ This means setting the variables "closed consultation" to its mode of 1, "effective support for the Commission's position" to its mean of 37.95 percent and the number of recitals to 27.41 .

${ }^{8}$ The $\log$ transformed variable is the natural $\log$ of $\mathrm{x}+1$, where $\mathrm{x}$ is the number of groups consulted in an open consultation. The addition of 1 means that we obtain a value for the cases in which no groups were consulted and also that we avoid using the part of the natural $\log$ function between 0 and 1 that increases very sharply. In line with the results presented, this log transformed variable was associated with a 
significant $(\mathrm{p}=.01)$ positive effect in the logit model (Model 1 of Table 3$)$ and a significant $(\mathrm{p}<.01)$ negative effect in the Tobit model (Model 2 of Table 3). 